\title{
Using COSMO-RS to design choline chloride pharmaceutical eutectic solvents
}

\author{
Dinis O. Abranches a , Marcos Larriba ${ }^{\text {b }}$, Liliana P. Silva ${ }^{a}$, Manuel Melle-Franco a, \\ José F. Palomar ${ }^{c}$, Simão P. Pinho ${ }^{\text {d, e }}$, João A.P. Coutinho ${ }^{\text {a, * }}$ \\ a CICECO, Aveiro Institute of Materials, Department of Chemistry, University of Aveiro, 3810-193, Aveiro, Portugal \\ ${ }^{\mathrm{b}}$ Department of Chemical Engineering and Materials, Faculty of Chemical Sciences, Complutense University of Madrid, 28040, Madrid, Spain \\ ${ }^{\text {c }}$ Departamento de Ingeniería Química, Universidad Autónoma de Madrid, 28049, Madrid, Spain \\ d Associate Laboratory LSRE-LCM, Department of Chemical and Biological Technology, Polytechnic Institute of Bragança, Portugal \\ ${ }^{\mathrm{e}}$ Mountain Research Center, CIMO, Polytechnic Institute of Bragança, Portugal
}

\section{A R T I C L E I N F O}

\section{Article history:}

Received 6 January 2019

Received in revised form 2 June 2019

Accepted 4 June 2019

Available online 6 June 2019

Keywords:

COSMO-RS

Green solvents

Predictive model

Pharmaceuticals

\begin{abstract}
A B S T R A C T
Deep eutectic solvents (DES) present interesting properties, mostly connected to their solvation ability, and have been subject to much research in the recent past. Currently, the discovery of new eutectic solvents is accomplished by experimentally measuring the eutectic point of random systems, often using choline chloride as a hydrogen bond acceptor. In this work, the eutectic temperatures of new choline chloride-based eutectic systems were experimentally assessed. These data, along with other previously reported in the literature, were used to evaluate a method based on COSMO-RS to predict the eutectic temperature of choline-chloride based mixtures. The predictive methodology herein developed allows for the quick scanning of a large matrix of systems in order to identify those more promising to be in the liquid state at a given temperature. To validate this method, the eutectic temperature of pharmaceutical drug mixtures was predicted and, then, assessed experimentally, showing that COSMO-RS is useful in the design of liquid drug-based formulations.
\end{abstract}

๑) 2019 Elsevier B.V. All rights reserved.

\section{Introduction}

Deep eutectic solvents (usually shortened to DES) are a relatively new class of green solvents that were first proposed by Abbott et al., in 2003 [1]. Their liquid state at operation temperature arises from the mixing of two or more solid components (typically hydrogen bond acceptors and donors) presenting a eutectic temperature at or below the operation temperature. In this way, what is commonly named deep eutectic solvents are eutectic mixtures that are liquid at the operation temperature, where the prefix deep, although disputable [2], can be understood in two ways: to highlight the fact that these are eutectic mixtures that have large negative deviations from ideality, or to emphasize that the eutectic melting temperature is significantly lower than that of the original components [3].

There has been a lot of scientific interest in this type of mixtures and comprehensive reviews are available [4-10]. A wide range of

\footnotetext{
* Corresponding author.

E-mail address: jcoutinho@ua.pt (J.A.P. Coutinho).
}

applications for these systems has been proposed and extensively studied. To conform to the status of a green solvent, it is common to prepare deep eutectic solvents using non-toxic, cheap substances. Following this line of thought, the most recurrent substance used in DES research is choline chloride, which acts as a hydrogen bond acceptor. It takes the form of deliquescent crystals, it is non-toxic and the DES prepared from it are, in general, non-toxic and biodegradable $[11,12]$. It is believed that its chemical structure allows for a great deal of hydrogen bonding with other substances and generally produces eutectic mixtures with interesting properties, in particular, good solvation abilities that can be tailored by choosing the appropriated hydrogen bond donor and its proportion.

A particular area of DES research is concerned with pharmaceutical compounds [13-16]. More specifically, the liquefaction of pharmaceutical drugs by the addition of a second component can solve problems such as poor solubility and bioavailability or polymorph instability. This, in turn, would solve non-optimal dosage problems, reducing wastes, and increasing the shelf life where crystalline morphology changes are an issue. As such, this work has 
a particular emphasis on the prediction of melting temperatures of binary systems consisting of choline chloride and a pharmaceutical ingredient.

Considering the interest in choline chloride-based deep eutectic solvents, it would be quite valuable to have a method able to predict the eutectic point of these systems and, thus, support the design of novel DES. The two pillars of such a development are (i) the knowledge of the melting temperature and enthalpy of the pure components and (ii) the ability to predict with enough accuracy their activity coefficients. In this perspective, the decomposition of choline chloride upon melting would hamper any attempt to search for that method. Recently, however, Fernandez et al. [17] were able to indirectly assess the melting temperature and enthalpy of choline chloride from solid-liquid equilibrium (SLE) data of a large number of systems. These properties were further appraised by Martins et al. [2] Concerning the activity coefficients, the predictive model COSMO-RS, based on quantum chemistry, has been extensively used in the study of DES [18-29], but generally focusing in applications and/or specific systems and not in the analysis of phase diagrams, or in the prediction of eutectic points, as will be here explored.

The present work aims at evaluating the ability of COSMO-RS to predict the eutectic temperature of choline chloride-based eutectic mixtures. For that purpose, a database of eutectic points was built from data collected from the open literature and supplemented by a considerable number of novel data measured in this work. The choline chloride was modelled in the COSMO-RS framework as either a single ion pair or two separated ions, comparing the two approaches. The predictive methodology was validated in the design of new pharmaceutical based DES by initially predicting the eutectic temperature of mixtures not previously studied and, then, measuring it experimentally, assessing the quality of the predictions by comparing both sets.

\section{Experimental}

In order to develop a suitable method to predict eutectic temperatures, a database on the melting temperatures of the pure compounds as well as of several choline chloride-based mixtures was assembled from literature data, and further extended measuring such data for new systems studied in this work.

\subsection{Chemicals}

The source and purity of the compounds used in this work are detailed in Table 1, as well as their melting properties, taken from the literature. Before use, each compound was dried under vacuum $(0.1 \mathrm{~Pa}$ and $298.15 \mathrm{~K})$ and constant stirring for at least $72 \mathrm{~h}$. The water content of all compounds was determined using a Metrohm 831 Karl Fischer coulometer, with the analyte Hydranal Coulomat AG from Riedel-de-Haën and found to be lower than 600 ppm for all compounds.

\subsection{Phase diagrams measurement}

All mixtures were prepared by weighting, inside a dry-argon glove-box and at room temperature, the amounts of each pure component using an analytical balance (model ALS 220-4 N from Kern) with an accuracy of $\pm 0.002 \mathrm{~g}$. Whenever possible, all samples were heated under stirring until complete melting, and then recrystallized. The solid-liquid phase diagrams were measured using two different methods, described below, depending on the physical state of the final mixture. Both procedures were repeated at least three times and the estimated reproducibility of the measurements is $2.0 \mathrm{~K}$.

For the mixtures with a paste-like consistency, a visual method with an oil bath previously described elsewhere [30] was employed. The mixtures were gradually heated until complete melting and the temperature was controlled with a PT100 probe (previously calibrated) with a precision of $\pm 0.1 \mathrm{~K}$.

For the remaining mixtures, the recrystallized solid was crushed in a mortar inside a glove-box and the powder was filled into a glass capillary. The solid-liquid phase diagrams were measured using a melting point device, model $\mathrm{M}-565$ by Buchi $(100-240 \mathrm{~V}$, $50-60 \mathrm{~Hz}, 150 \mathrm{~W})$, with a temperature resolution of $0.1 \mathrm{~K}$, as previously described [30], and a temperature gradient of $0.1 \mathrm{~K} \mathrm{~min}^{-1}$.

\section{Model}

\subsection{Thermodynamic framework}

To describe a eutectic type solid-liquid phase diagram, the equilibrium curve for each component can be calculated by Ref. [43]:

$\ln \left(x_{i} \cdot \gamma_{i}\right)=\frac{\Delta_{m} H_{i}}{R} \cdot\left(\frac{1}{T_{m, i}}-\frac{1}{T}\right)+\frac{\Delta_{m} C p_{i}}{R} \cdot\left(\frac{T_{m, i}}{T}-\ln \frac{T_{m, i}}{T}-1\right)$

where $x_{i}$ is the mole fraction of component $i, \gamma_{i}$ its activity coefficient, $\Delta_{m} H_{i}$ is the melting enthalpy of pure component $i$ and $T_{m, i}$ its

Table 1

Name, CAS number, supplier and purity of the compounds experimentally studied in this work, along with their melting properties and literature source.

\begin{tabular}{|c|c|c|c|c|c|c|}
\hline Compound & CAS Number & Supplier & Purity (\%) & $T_{m} / \mathrm{K}$ & $\Delta_{m} H /(\mathrm{kJ} / \mathrm{mol})$ & Reference \\
\hline Choline Chloride & $67-48-1$ & Acros Organics & 98 & 597 & 4.30 & [17] \\
\hline Urea & $57-13-6$ & Analar & 99.5 & 406.5 & 14.79 & [31] \\
\hline Methylurea & $598-50-5$ & Acros Organics & 97 & 373.8 & 15.75 & [31] \\
\hline 1,1-Dimethylurea & $598-94-7$ & Acros Organics & 98 & 454.0 & 29.11 & [31] \\
\hline 1,3-Dimethylurea & $96-31-1$ & Acros Organics & 98 & 379.5 & 13.62 & [31] \\
\hline Thiourea & $62-56-6$ & Acros Organics & 99 & 444.7 & 15.64 & [32] \\
\hline Benzoic Acid & $65-85-0$ & Acros Organics & 99 & 395.4 & 17.10 & [33] \\
\hline Salicylic Acid & $69-72-7$ & Acofarma & 99 & 432.5 & 23.05 & [34] \\
\hline 5-Phenylvaleric Acid & $2270-20-4$ & Aldrich & 99 & 332.0 & 23.40 & [35] \\
\hline D-Mannitol & $69-65-8$ & Sigma-Aldrich & 99 & 437.3 & 54690 & [36] \\
\hline Meso-erythritol & $149-32-6$ & Alfa Aesar & $>99$ & 391.2 & 38.90 & [37] \\
\hline Malonic Acid & $141-82-2$ & Fluka & $>98$ & 407.5 & 23.10 & [38] \\
\hline Citric Acid & $77-92-9$ & Fischer Scientific & 100 & 426.2 & 26.70 & [39] \\
\hline Succinic Acid & $110-15-6$ & Merck & 99 & 455.2 & 34.00 & [40] \\
\hline Acetamide & $60-35-5$ & Acros Organics & 99 & 354.1 & 15.50 & [41] \\
\hline Benzamide & $51-21-0$ & Acros Organics & 99 & 403.0 & 23.76 & [42] \\
\hline
\end{tabular}


a)

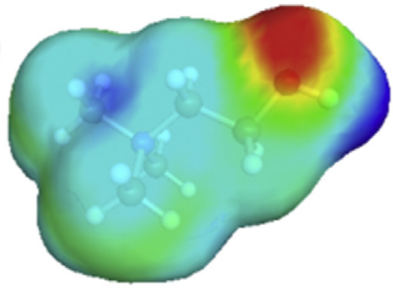

b)

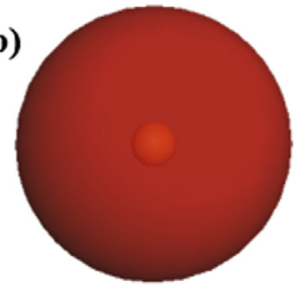

Fig. 1. Sigma surfaces of the choline ion (a) and of the chloride ion (b) as calculated using TURBOMOLE and used as input to the COSMO-RS model (model $\mathrm{A}+\mathrm{B}$ ). The tota electronic energy is $-328.8959 \mathrm{Ha}$ and $-460.4521 \mathrm{Ha}$, respectively.

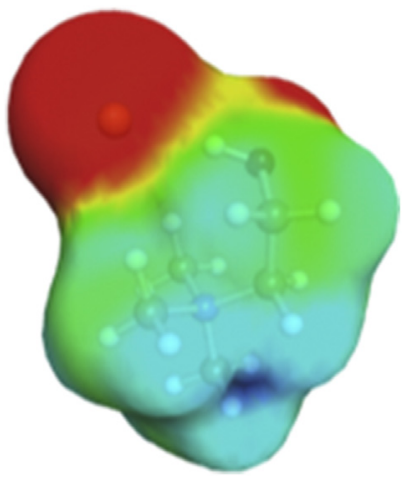

Fig. 2. Sigma surface of the choline chloride ion pair as calculated using TURBOMOLE and used as input to the COSMO-RS model (model AB). The total electronic energy is $-789.3558 \mathrm{Ha}$.

melting temperature, $R$ is the ideal gas constant, $T$ is the absolute temperature and $\Delta_{m} C p_{i}$ is the heat capacity change of component $i$ upon melting. Notice that Equation (1) does not describe solid-solid transitions, which are not present in the systems herein studied.

The influence of the heat capacity term tends to be very small in most systems [44,45], in particular if the temperature is not too far from the melting temperature of the pure compound. Moreover, the $\Delta_{m} C p$ value is not available for most compounds used in this work due to a variety of reasons, one of which is thermal decomposition, as is the case of choline chloride. Taking all this into consideration and for the purpose of this study, the equilibrium equation used is a reduced form of equation (1):

$\ln \left(x_{i} \cdot \gamma_{i}\right)=\frac{\Delta_{m} H_{i}}{R} \cdot\left(\frac{1}{T_{m, i}}-\frac{1}{T}\right)$

For an ideal system it becomes:

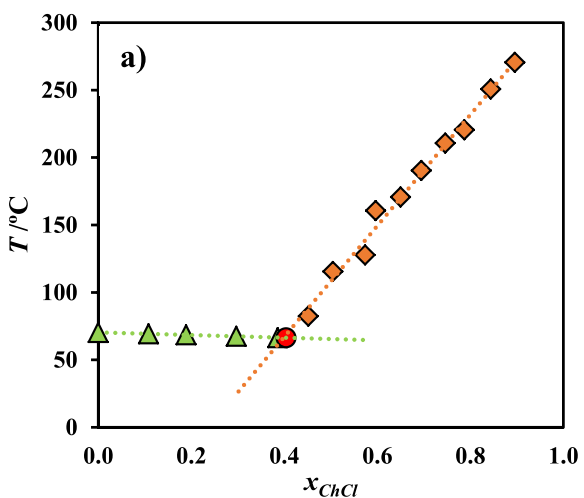

$\ln \left(x_{i}\right)=\frac{\Delta_{m} H_{i}}{R} \cdot\left(\frac{1}{T_{m, i}}-\frac{1}{T}\right)$

In order to calculate the solid-liquid phase diagrams, it is necessary to know the melting properties (temperatures and enthalpies) of each component. These properties are reported in Table 1 for the compounds studied experimentally in this work, and in Table S1 for the remaining ones.

\subsection{COSMO-RS}

COSMO-RS, short for Conductor like Screening Model for Real Solvents, is a thermodynamics model, based on quantum mechanics, that predicts the chemical potentials of individual components in liquid mixtures [46,47]. This model considers the polarization charge-density $(\sigma)$ to build $\sigma$-profiles of molecules. From those, the chemical potentials of the components can be calculated considering pair-wise interactions and from these, the activity coefficients.

In the present work, COSMO-RS was used through the software COSMOtherm $[48,49]$ with the parametrization BP_TZVP_ C30_1701.ctd. Each input file needed to apply the model was prepared using the software TmoleX [50,51], adopting a DFT with the B-P86 functional level of theory and a def-TZVP basis set.

It should be noted that COSMO-RS is not particularly suitable for calculations with ionic species [30,52]. Attempting to minimize this problem, two distinct approaches are investigated in this work. The first considers choline chloride as two individual ions, each molecular file being optimized with TURBOMOLE (model A $+B$ ) while in the second approach, choline chloride is dealt as an ion pair whose structure is based on the work by Ashworth et al. [53], and then optimized using TURBOMOLE (model AB). Both sigma surfaces obtained are presented in Figs. 1 and 2.

Regarding the second component in the binary mixtures, its sigma surface was calculated considering it as a single molecular species. Thus, when the second component was ionic, it was modelled as an ion pair, much like choline chloride is modelled in the AB model. Moreover, other geometries (Fig. S1) were tested for choline chloride. Since the results thus obtained were much poorer, these are not further analysed in this work.

\section{Results and discussion}

\subsection{Experimental eutectic points}

The experimental eutectic temperatures of the systems being

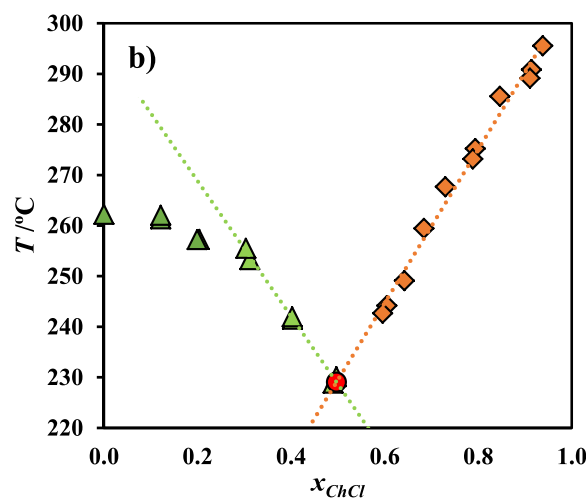

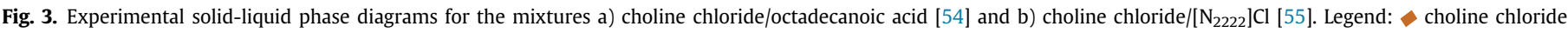

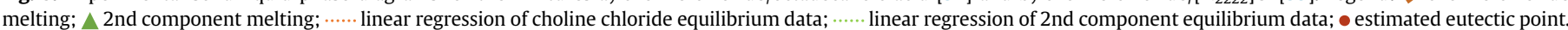


Table 2

Eutectic points of choline chloride-based systems (mole fraction and temperature) and standard error (S), along with source of the SLE phase diagram.

\begin{tabular}{|c|c|c|c|c|c|}
\hline 2nd Component & Reference & $x_{\text {eut }}$ & $S_{\text {xeut }}$ & $\begin{array}{l}T_{\text {eut }} \\
/{ }^{\circ} \mathrm{C}\end{array}$ & $\begin{array}{l}S_{\text {Teut }} \\
/^{\circ} \mathrm{C}\end{array}$ \\
\hline Urea & This Work & 0.42 & 0.01 & 16 & 3 \\
\hline Methylurea & This Work & 0.40 & 0.01 & 31 & 3 \\
\hline 1,1-Dimethylurea & This Work & 0.38 & 0.03 & 119 & 7 \\
\hline 1,3-Dimethylurea & This Work & 0.39 & 0.01 & 56 & 2 \\
\hline Thiourea & This Work & 0.42 & 0.03 & 100 & 7 \\
\hline Decanoic Acid & [54] & 0.40 & 0.02 & 34 & 4 \\
\hline Dodecanoic Acid & [54] & 0.41 & 0.03 & 39 & 1 \\
\hline Tetradecanoic Acid & [54] & 0.51 & 0.03 & 52 & 1 \\
\hline Hexadecanoic Acid & [54] & 0.41 & 0.02 & 52 & 2 \\
\hline Octadecanoic Acid & [54] & 0.40 & 0.03 & 66 & 1 \\
\hline Tetradecanol & [54] & 0.44 & 0.02 & 30 & 2 \\
\hline Hexadecanol & [54] & 0.62 & 0.03 & 55 & 6 \\
\hline Octadecanol & [54] & 0.58 & 0.03 & 56 & 3 \\
\hline Benzoic Acid & This Work & 0.28 & 0.01 & 78 & 2 \\
\hline Salicylic Acid & This Work & 0.48 & 0.02 & 61 & 6 \\
\hline 5-Phenylvaleric Acid & This Work & 0.40 & 0.03 & 20 & 7 \\
\hline D-Mannitol & This Work & 0.50 & 0.02 & 112 & 4 \\
\hline Meso-erythritol & This Work & 0.44 & 0.02 & 78 & 6 \\
\hline $\mathbf{D}(+)$-Glucose & {$[30]$} & 0.53 & 0.02 & 55 & 4 \\
\hline$D(-)$-Fructose & [30] & 0.50 & 0.02 & 53 & 5 \\
\hline $\mathrm{D}(+)$-Sucrose & [30] & 0.54 & 0.03 & 58 & 8 \\
\hline $\mathrm{D}(+)$-Xylose & [30] & 0.49 & 0.01 & 47 & 4 \\
\hline Malonic Acid & This Work & 0.48 & 0.02 & 12 & 4 \\
\hline Citric Acid & This Work & 0.68 & 0.04 & 79 & 6 \\
\hline Succinic Acid & This Work & 0.52 & 0.02 & 66 & 4 \\
\hline Choline Acetate & [17] & 0.44 & 0.01 & 35 & 3 \\
\hline$\left[\mathrm{N}_{4444}\right] \mathrm{Cl}$ & [17] & 0.50 & 0.02 & 47 & 4 \\
\hline [BzCh] Cl & [17] & 0.41 & 0.01 & 31 & 3 \\
\hline$\left[\mathrm{C}_{4} \mathrm{mpyr}\right] \mathrm{Cl}$ & [17] & 0.63 & 0.02 & 148 & 2 \\
\hline$\left[\mathrm{C}_{2} \mathrm{mim}\right] \mathrm{Cl}$ & [17] & 0.44 & 0.01 & 30 & 4 \\
\hline$\left[\mathrm{C}_{2} \mathrm{OHmim}\right] \mathrm{Cl}$ & [17] & 0.55 & 0.03 & 49 & 3 \\
\hline$\left[\mathrm{N}_{2222}\right] \mathrm{Cl}$ & [55] & 0.50 & 0.02 & 229 & 3 \\
\hline$\left[\mathrm{N}_{3333}\right] \mathrm{Cl}$ & [55] & 0.54 & 0.03 & 201 & 3 \\
\hline Acetamide & This Work & 0.44 & 0.02 & 48 & 2 \\
\hline Benzamide & This Work & 0.42 & 0.02 & 89 & 3 \\
\hline
\end{tabular}

studied were obtained from their solid-liquid phase diagrams, which were either taken from the literature or measured in this work. To do so, both component curves were regressed linearly, using the method of least squares, and their interception was regarded as the experimental eutectic point. In a few cases, one of the SLE curves (or both) differed significantly from a straight line. In these systems, not all the experimental data were used. Instead, only the data closer to the eutectic point were regressed. The systems choline chloride/octadecanoic acid [54] and choline chloride/ [N $\mathrm{N}_{2222}$ ] Cl [55] are displayed in Fig. 3 to exemplify both situations.

To assign an uncertainty value to the estimated eutectic temperature and composition, a propagation of uncertainty method was used and is detailed in Supporting Information (section S3). The eutectic points estimated from SLE phase diagrams, either measured in this work or taken from literature, along with their standard errors are reported in Table 2, noticing that these errors are quite small.

\subsection{COSMO-RS predictions}

For each system reported in Table 2, its SLE phase diagram was calculated with COSMO-RS considering the two approaches adopted for choline chloride. For comparison purposes, the ideal SLE diagram was also calculated, using equation (3). These diagrams are presented in Fig. S2 of the Supporting Information. Table 3 summarizes all the calculated eutectic temperatures.

It is evident that the present version of COSMO-RS is unable to adequately predict the solid-liquid phase diagrams for all systems studied. Moreover, COSMO-RS, especially with the model A $+\mathrm{B}$,
Table 3

Experimental and predicted eutectic temperatures estimated considering the ideal liquid mixture and using COSMO-RS with model A $+\mathrm{B}$ or model AB.

\begin{tabular}{|c|c|c|c|c|}
\hline 2nd Component & $\begin{array}{l}\text { Experimental } \\
T_{\text {eut }} /{ }^{\circ} \mathrm{C}\end{array}$ & $\begin{array}{l}\text { Ideal } T_{\text {eut }} \\
/{ }^{\circ} \mathrm{C}\end{array}$ & $\begin{array}{l}\text { Model } \mathrm{A}+\mathrm{B} T_{\text {eut }} \\
/{ }^{\circ} \mathrm{C}\end{array}$ & $\begin{array}{l}\text { Model AB } T_{\text {eut }} \\
{ }^{\circ} \mathrm{C}\end{array}$ \\
\hline Urea & 16 & 73.0 & -178.6 & 14.9 \\
\hline Methylurea & 31 & 56.3 & -131.5 & 23.6 \\
\hline 1,1-Dimethylurea & 119 & 126.3 & 68.0 & 130.9 \\
\hline 1,3-Dimethylurea & 56 & 54.9 & -171.8 & 47.7 \\
\hline Thiourea & 100 & 95.2 & & $\longrightarrow$ \\
\hline Decanoic Acid & 34 & 17.8 & - & -6.0 \\
\hline Dodecanoic Acid & 39 & 32.1 & & 34.9 \\
\hline Tetradecanoic Acid & 52 & 41.2 & - & 47.5 \\
\hline Hexadecanoic Acid & 52 & 51.9 & - & 61.2 \\
\hline Octadecanoic Acid & 66 & 59.7 & -27.2 & 67.6 \\
\hline Tetradecanol & 30 & 29.0 & -10.2 & 37.8 \\
\hline Hexadecanol & 55 & 34.0 & -69.7 & 48.4 \\
\hline Octadecanol & 56 & 43.4 & 47.1 & 56.9 \\
\hline Benzoic Acid & 78 & 72.0 & & -45.2 \\
\hline Salicylic Acid & 61 & 104.6 & - & -107.0 \\
\hline $\begin{array}{l}\text { 5-Phenylvaleric } \\
\text { Acid }\end{array}$ & 20 & 37.1 & 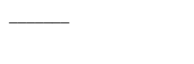 & -11.6 \\
\hline D-Mannitol & 112 & 134.2 & -20.5 & 100.3 \\
\hline Meso-erythritol & 78 & 91.9 & -143.6 & 32.3 \\
\hline $\mathrm{D}(+)$-Glucose & 55 & 108.4 & & -7.4 \\
\hline $\mathrm{D}(-)$-Fructose & 53 & 79.9 & - & -139.7 \\
\hline $\mathrm{D}(+)$-Sucrose & 58 & 139.4 & - & -68.7 \\
\hline $\mathrm{D}(+)$-Xylose & 47 & 104.7 & -78.3 & 49.6 \\
\hline Malonic Acid & 12 & 89.33 & & \\
\hline Citric Acid & 79 & 106.0 & & 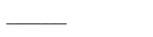 \\
\hline Succinic Acid & 66 & 132.7 & & - \\
\hline Choline Acetate & 35 & 30.8 & - & 27.0 \\
\hline$\left[\mathrm{N}_{4444}\right] \mathrm{Cl}$ & 47 & 41.3 & $\longrightarrow$ & 60.0 \\
\hline [BzCh] Cl & 31 & 24.4 & -85.2 & 21.0 \\
\hline$\left[\mathrm{C}_{4} \mathrm{mpyr}\right] \mathrm{Cl}$ & 148 & 139.9 & 90.5 & 146.8 \\
\hline$\left[\mathrm{C}_{2} \mathrm{mim}\right] \mathrm{Cl}$ & 30 & 23.3 & -131.7 & 26.0 \\
\hline$\left[\mathrm{C}_{2} \mathrm{OHmim}\right] \mathrm{Cl}$ & 49 & 54.3 & 7.6 & 57.8 \\
\hline$\left[\mathrm{N}_{2222}\right] \mathrm{Cl}$ & 229 & 192.7 & 168.9 & 196.6 \\
\hline$\left[\mathrm{N}_{3333}\right] \mathrm{Cl}$ & 201 & 187.1 & 173.0 & 205.5 \\
\hline Acetamide & 48 & 43.4 & -68.0 & 32.2 \\
\hline Benzamide & 89 & 87.4 & -91.0 & 71.2 \\
\hline
\end{tabular}

systematically underestimates the values of the activity coefficients for both components, overestimating the non-ideality of the mixtures, leading to eutectic temperatures much lower than those obtained experimentally. For a number of systems, irrespective of the model used to describe choline chloride $(A+B$ or $A B)$, this underestimation of the activity coefficients led to SLE diagrams consisting of two lines that do not intercept each other. Contrasting with this behaviour, the $A B$ model, specifically for fatty acids/alcohols, predicted choline chloride to have large positive deviations from ideality. Both situations are exemplified in Fig. 4. Notice how COSMO-RS largely underestimates the activity coefficients in the first case (Fig. 4a) and how it largely overestimates the activity coefficient of choline chloride in the second case, using model $A B$ (Fig. 4b). In some cases, immiscibility was also predicted.

Analyzing Table 3 , it stands out that the model $A B$ produces remarkably better results than the model $A+B$. From all thirty-five systems studied in this work, model $A B$ only failed to predict the eutectic point, predicting a gap instead, in four of them (mainly for systems with policarboxylic acids). Its mean absolute error, defined as:

$M A E=\sum\left|T_{\text {model }, i}-T_{\text {experimental }, i}\right| / N_{\text {systems }}$

is $31^{\circ} \mathrm{C}$. However, the model displayed abnormal innacurate predictions for close-ring sugars (glucose, frutose and saccarose), and aromatica acids (benzoic and salicylic acids). The difficulties herein encountered to describe the choline chloride/sugar systems have 

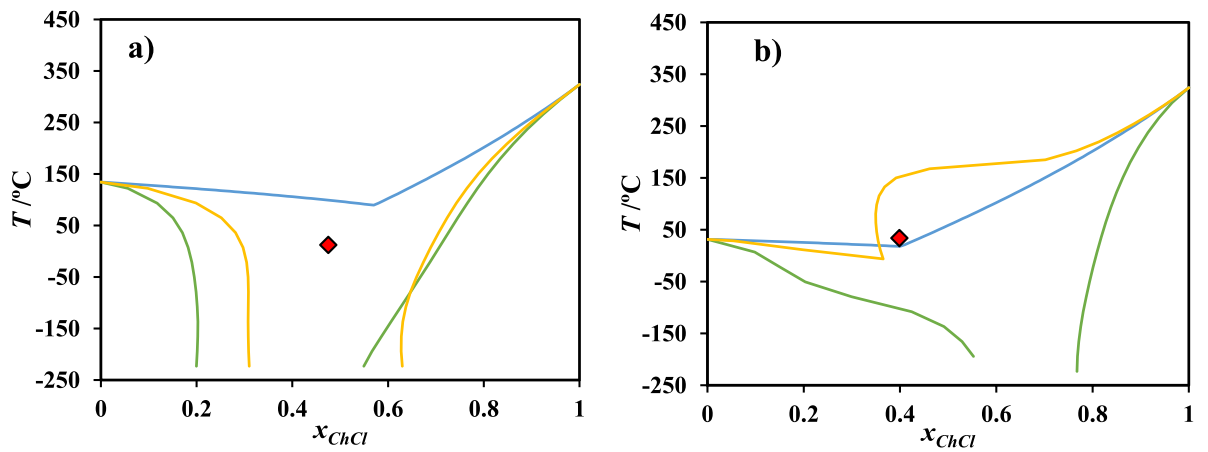

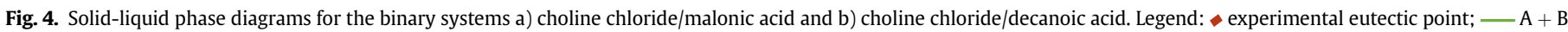
model; __ AB model; __ ideal liquid phase model.

already been reported in the literature along with fine-tuning of COSMO-RS parameters to overcome them [30]. If these five systems are disregarded as outliers, the mean deviation of the AB model is decreased to just $12{ }^{\circ} \mathrm{C}$. Fig. 5 illustrates these results. Although these results, in terms of absolute average deviations, do not seem to be much better than those obtained considering an ideal liquid mixture, even since as shown by us [2] many of these systems do not show a significant deviation to ideal behaviour, a simular representation presented in Fig. S4 shows that as the non ideality increases COSMO-RS is able to capture this for most systems with success.

Contrary to the $A B$ model, from the thirty-five binary systems studied in this work, model A + B was only able to predict the eutectic point for nineteen of them. In the remaining sixteen systems, this model overly underestimated the activity coefficients,

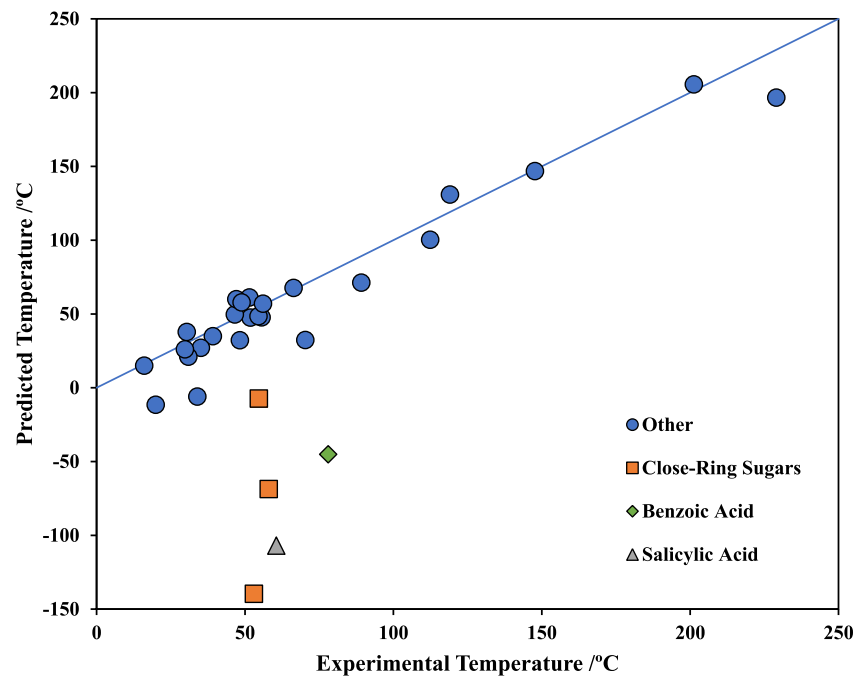

Fig. 5. Predicted vs experimental eutectic temperatures by COSMO-RS (model AB). Benzoic acid, salicylic acid and close-ring sugars are highlighted. The full line represents the equality between predicted and experimental temperatures. leading to gaps in the diagrams that are impossible to close. Moreover, the eutectic temperatures predicted are, in general, too low when compared to those obtained experimentally, with a mean error of $112{ }^{\circ} \mathrm{C}$ (as per equation (4)). As such, the $\mathrm{AB}$ model greatly suprasses the predictive ability of the $A+B$ model and is the one chosen to predict the eutectic temperature of new novel eutectic solvents of pharmaceutical relevance.

\subsection{Design of novel pharmaceutical-based eutectic solvents}

To validate the predictive methodology herein developed, the eutectic temperature of four novel pharmaceutical-based systems was estimated. Then, their solid-liquid diagrams were measured, as described in section 2, and the results compared with the predictions.

The chosen substances were acetylsalicylic acid, ibuprofen, ketoprofen and paracetamol. Pertinent information regarding these compounds is given in Table 4.

The experimental eutectic temperature obtained for each system, both experimentally and with model AB, is reported in Table 5, along with the experimental uncertainty (calculated as described in section S3 of the supplementary information). The SLE phase diagrams are displayed in Fig. 6.

In general, the predictions obtained through COSMO-RS were fairly accurate, with a mean average error (estimated by equation (4)) of $6^{\circ} \mathrm{C}$. The largest deviation was obtained for the choline

Table 5

Experimental eutectic temperature, along with its standard uncertainty $(S)$ and the eutectic temperature predicted by COSMO-RS (model AB), along with the absolute difference between it and the experimental value, for pharmaceutical based systems.

\begin{tabular}{lllll}
\hline System & $\underline{T}_{\text {eut }}$ Experimental $/{ }^{\circ} \mathrm{C}$ & $\begin{array}{l}S_{\text {Teut }} \\
/{ }^{\circ} \mathrm{C}\end{array}$ & $\begin{array}{l}T_{\text {eut }} \text { Model AB } \\
/{ }^{\circ} \mathrm{C}\end{array}$ & $\begin{array}{l}\text { Error } \\
/{ }^{\circ} \mathrm{C}\end{array}$ \\
\hline Acetylsalicylic Acid & 63 & 2 & 48.9 & 14 \\
Ibuprofen & 51 & 3 & 52.1 & 1 \\
Ketoprofen & 75 & 2 & 78.4 & 3 \\
Paracetamol & 39 & 8 & 43.5 & 5 \\
\hline
\end{tabular}

Table 4

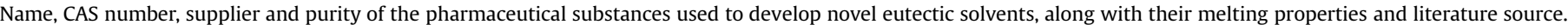

\begin{tabular}{|c|c|c|c|c|c|c|}
\hline Compound & CAS Number & Supplier & Purity (weight \%) & $\begin{array}{l}T_{m} \\
/ \mathrm{K}\end{array}$ & $\begin{array}{l}\Delta_{m} H \\
/(\mathrm{kJ} / \mathrm{mol})\end{array}$ & Reference \\
\hline Acetylsalicylic Acid & $50-78-2$ & Sigma-Aldrich & $>99$ & 414.0 & 29.80 & [56] \\
\hline Ibuprofen & $15687-27-1$ & Sigma-Aldrich & 98 & 350.4 & 39.50 & {$[57]$} \\
\hline Ketoprofen & $22071-15-4$ & Alfa Aesar & $>98$ & 368.0 & 37.30 & [58] \\
\hline Paracetamol & $103-90-2$ & Sigma-Aldrich & 99 & 443.0 & 26.20 & [59] \\
\hline
\end{tabular}



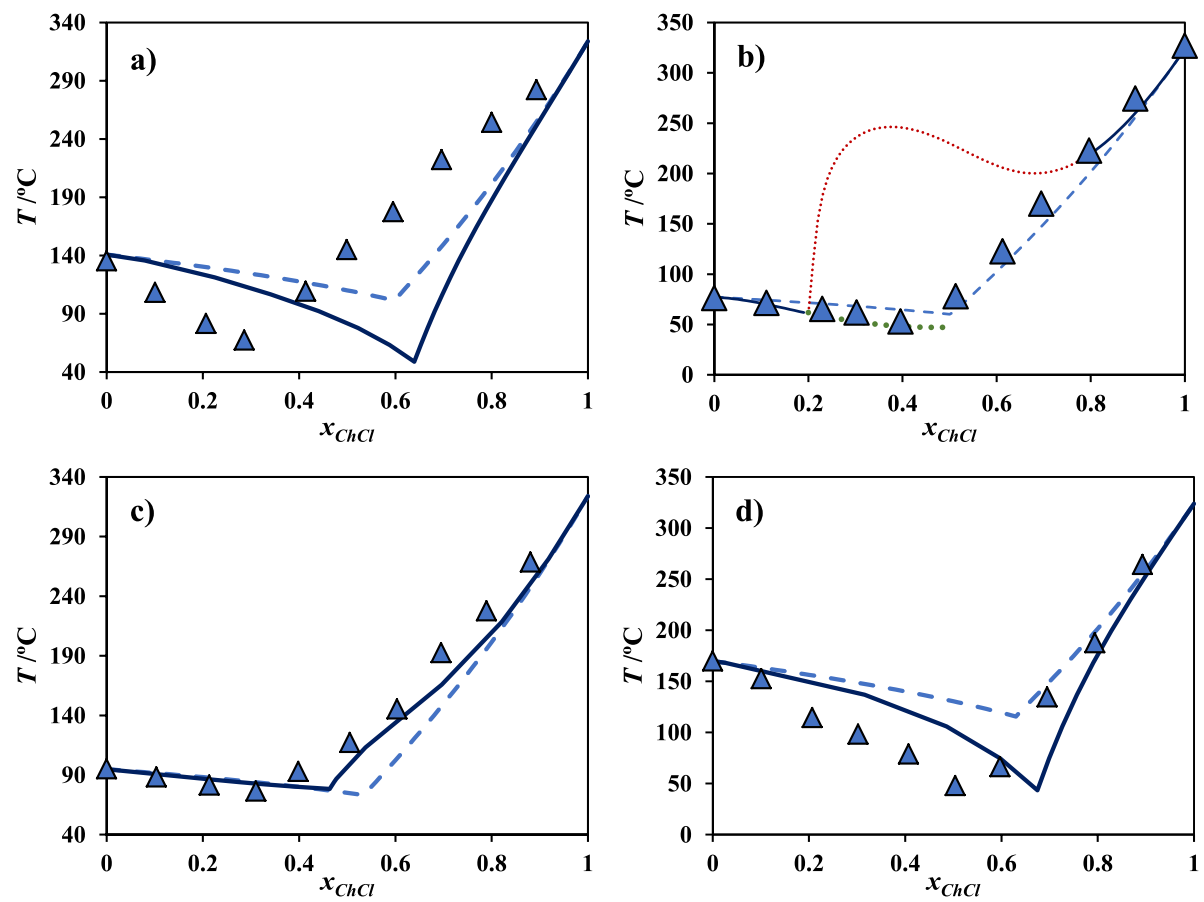

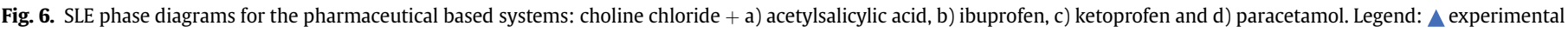
data; - - - - ideal liquid phase model; _ _ COSMO-RS (AB model); ...... highlighted SLE data; ....... ibuprofen curve extended beyond the predicted eutectic point.

chloride/acetylsalicylic acid system. This was expected, since model $A B$ had already shown severe inaccuracy when predicting the choline chloride/aromatic acids systems. The current COSMO-RS parameterization seems to have problems in dealing with aromatic acids. Abbott et al. [13] reported mixtures of choline chloride with acetylsalicylic acid to be liquid at room temperature but using dry compounds this could never be achieved in our study, the actual eutectic temperature observed are well above room temperature.

COSMO-RS can in general provide semi-quantitative predictions that can be useful for scanning a large number of systems, selecting a solvent or, as shown in this work, the melting temperature of a mixture. However its behaviour is often unpredictably unreliable, as shown above for the aromatic acids, or in this results for the ibuprofen where the crystallization curve of choline on this mixture is clearly physically unsound as result of a non-monotonic behaviour of the activities of the compound predicted by the model (as shown in Fig. S3), which results in the odd behaviour of the SLE diagram reported in Fig. 6b. We chose, however, to present the ibuprofen curve extending beyond the predicted eutectic composition, showing its good agreement with the experimental data and that the eutectic point, were the cholinium chloride curve correctly described, would be not far from the experimental value. The results presented in Fig. 6, most with significant deviations to ideality, further stress the advantage of using COSMO-RS, in spite of its problems, on the prediction of the eutectic temperatures of mixtures when compared with the ideal liquid mixture predictions.

\section{Conclusion}

Based on COSMO-RS, a methodology to predict new choline chloride-based eutectic solvents has been developed. Two different choline chloride models were investigated, the A $+\mathrm{B}$ model, where choline chloride is treated as two different ions, and the AB model, where choline chloride is treated as an ion pair. Both models were used to predict eutectic temperatures of several binary systems.
Model A + B was shown to be very inaccurate, underestimating severely the activity coefficients, leading to gaps in the diagrams for many of them. On the other hand, model AB provided a reasonable description of most systems studied, with exception of those including close-ring sugars, and aromatic acids (salicylic acid and benzoic acid). The mean error of the $\mathrm{A}+\mathrm{B}$ model was $112^{\circ} \mathrm{C}$ while the $\mathrm{AB}$ model had a mean absolute error of $31{ }^{\circ} \mathrm{C}\left(12^{\circ} \mathrm{C}\right.$ if the outliers are removed).

The methodology developed in this work was validated by predicting eutectic temperatures for new systems containing pharmaceutical compounds as the second component (acetylsalicylic acid, ibuprofen, ketoprofen and paracetamol). The SLE phase diagrams for these systems were then experimentally measured and a mean absolute error of just $6{ }^{\circ} \mathrm{C}$ was obtained. The methodology herein developed can be used in future works to predict new eutectic solvents without the need of fastidious experimental trial and error measurements.

\section{Acknowledgements}

This work was developed in the scope of the project CICECO Aveiro Institute of Materials, POCI-01-0145-FEDER-007679 (Ref. FCT UID/CTM/50011/2013) and Associate Laboratory LSRE-LCM, POCI01-0145-FEDER-006984 (Ref. FCT UID/EQU/50020/2013), and project MultiBiorefinery (POCI-01-0145-FEDER-016403), financed by national funds through the FCT/MEC and when appropriate cofinanced by FEDDER under the PT2020 Partnership Agreement. FCT is also acknowledged for funding the project DeepBiorefinery (PTDC/AGRTEC/1191/2014). Marcos Larriba also thanks Ministerio de Eduación, Cultura y Deporte of Spain for awarding him a José Castillejo postdoctoral mobility grant (CAS17/00018).

\section{Appendix A. Supplementary data}

Supplementary data to this article can be found online at https://doi.org/10.1016/j.fluid.2019.06.005. 


\section{References}

[1] A.P. Abbott, G. Capper, D.L. Davies, R.K. Rasheed, V. Tambyrajah, Novel solvent properties of choline chloride/urea mixtures, Chem. Commun. (2003) 70-71, https://doi.org/10.1039/b210714g.

[2] M.A.R. Martins, S.P. Pinho, J.A.P. Coutinho, Insights into the nature of eutectic and deep eutectic mixtures, J. Solut. Chem. (2018), https://doi.org/10.1007/ s10953-018-0793-1.

[3] A.P. Abbott, D. Boothby, G. Capper, D.L. Davies, R.K. Rasheed, Deep eutectic solvents formed between choline chloride and carboxylic acids: versatile alternatives to ionic liquids, J. Am. Chem. Soc. 126 (2004) 9142-9147, https:// doi.org/10.1021/ja048266j.

[4] Q. Zhang, K. De Oliveira Vigier, S. Royer, F. Jérôme, Deep eutectic solvents: syntheses, properties and applications, Chem. Soc. Rev. 41 (2012) 7108, https://doi.org/10.1039/c2cs35178a.

[5] B. Tang, K.H. Row, Recent developments in deep eutectic solvents in chemical sciences, Monatshefte Für Chemie - Chem. Mon. 144 (2013) 1427-1454, https://doi.org/10.1007/s00706-013-1050-3.

[6] E.L. Smith, A.P. Abbott, K.S. Ryder, Deep eutectic solvents (DESs) and their applications, Chem. Rev. 114 (2014) 11060-11082, https://doi.org/10.1021/ cr300162p.

[7] A. Paiva, R. Craveiro, I. Aroso, M. Martins, R.L. Reis, A.R.C. Duarte, Natural deep eutectic solvents - solvents for the 21 st century, ACS Sustain. Chem. Eng. 2 (2014) 1063-1071, https://doi.org/10.1021/sc500096j.

[8] D.V. Wagle, H. Zhao, G.A. Baker, Deep eutectic solvents: sustainable media for nanoscale and functional materials, Acc. Chem. Res. 47 (2014) 2299-2308, https://doi.org/10.1021/ar5000488.

[9] D. Carriazo, M.C. Serrano, M.C. Gutiérrez, M.L. Ferrer, F. del Monte, Deepeutectic solvents playing multiple roles in the synthesis of polymers and related materials, Chem. Soc. Rev. 41 (2012) 4996, https://doi.org/10.1039/ c2cs15353j.

[10] H. Zhao, G.A. Baker, Ionic liquids and deep eutectic solvents for biodiesel synthesis: a review, J. Chem. Technol. Biotechnol. 88 (2013) 3-12, https:// doi.org/10.1002/jctb.3935.

[11] P. de Morais, F. Gonçalves, J.A.P. Coutinho, S.P.M. Ventura, Ecotoxicity of cholinium-based deep eutectic solvents, ACS Sustain. Chem. Eng. 3 (2015) 3398-3404, https://doi.org/10.1021/acssuschemeng.5b01124.

[12] K. Radošević, M. Cvjetko Bubalo, V. Gaurina Srček, D. Grgas, T. Landeka Dragičević, I. Radojčić Redovniković, Evaluation of toxicity and biodegradability of choline chloride based deep eutectic solvents, Ecotoxicol. Environ. Saf. 112 (2015) 46-53, https://doi.org/10.1016/j.ecoenv.2014.09.034.

[13] A.P. Abbott, E.I. Ahmed, K. Prasad, I.B. Qader, K.S. Ryder, Liquid pharmaceuticals formulation by eutectic formation, Fluid Phase Equilib. 448 (2017) 2-8 https://doi.org/10.1016/j.fluid.2017.05.009.

[14] A.A. Barros, J.M. Silva, R. Craveiro, A. Paiva, R.L. Reis, A.R.C. Duarte, Green solvents for enhanced impregnation processes in biomedicine, Curr. Opin Green Sustain. Chem. 5 (2017) 82-87, https://doi.org/10.1016/ j.cogsc.2017.03.014.

[15] I.M. Aroso, R. Craveiro, Â. Rocha, M. Dionísio, S. Barreiros, R.L. Reis, A. Paiva A.R.C. Duarte, Design of controlled release systems for THEDES-therapeutic deep eutectic solvents, using supercritical fluid technology, Int. J. Pharm. 492 (2015) 73-79, https://doi.org/10.1016/j.ijpharm.2015.06.038.

[16] A.R.C. Duarte, A.S.D. Ferreira, S. Barreiros, E. Cabrita, R.L. Reis, A. Paiva, A comparison between pure active pharmaceutical ingredients and therapeutic deep eutectic solvents: solubility and permeability studies, Eur. J Pharm. Biopharm. 114 (2017) 296-304, https://doi.org/10.1016/ j.ejpb.2017.02.003.

[17] L. Fernandez, L.P. Silva, M.A.R. Martins, O. Ferreira, J. Ortega, S.P. Pinho, J.A.P. Coutinho, Indirect assessment of the fusion properties of choline chloride from solid-liquid equilibria data, Fluid Phase Equilib. 448 (2017) 9-14 https://doi.org/10.1016/j.fluid.2017.03.015.

[18] Z. Salleh, I. Wazeer, S. Mulyono, L. El-blidi, M.A. Hashim, M.K. Hadj-Kali, Efficient removal of benzene from cyclohexane-benzene mixtures using deep eutectic solvents - COSMO-RS screening and experimental validation, J. Chem. Thermodyn. 104 (2017) 33-44, https://doi.org/10.1016/ j.jct.2016.09.002.

[19] N.R. Rodriguez, T. Gerlach, D. Scheepers, M.C. Kroon, I. Smirnova, Experimental determination of the LLE data of systems consisting of \{hexane benzene + deep eutectic solvent $\}$ and prediction using the Conductor-like Screening Model for Real Solvents, J. Chem. Thermodyn. 104 (2017) 128-137, https://doi.org/10.1016/j.jct.2016.09.021.

[20] S. Mulyono, H.F. Hizaddin, I.M. Alnashef, M.A. Hashim, A.H. Fakeeha, M.K. Hadj-Kali, Separation of BTEX aromatics from n-octane using a (tetrabutylammonium bromide + sulfolane) deep eutectic solvent - experiments and COSMO-RS prediction, RSC Adv. 4 (2014) 17597, https://doi.org/10.1039/ c4ra01081g.

[21] H.F. Hizaddin, M. Sarwono, M.A. Hashim, I.M. Alnashef, M.K. Hadj-Kali, Coupling the capabilities of different complexing agents into deep eutectic solvents to enhance the separation of aromatics from aliphatics, J. Chem. Thermodyn. 84 (2015) 67-75, https://doi.org/10.1016/j.jct.2014.12.024.

[22] H.F. Hizaddin, A. Ramalingam, M.A. Hashim, M.K.O. Hadj-Kali, Evaluating the performance of deep eutectic solvents for use in extractive denitrification of liquid fuels by the conductor-like screening model for real solvents, J. Chem. Eng. Data 59 (2014) 3470-3487, https://doi.org/10.1021/je5004302.
[23] M. Hayyan, Y.P. Mbous, C.Y. Looi, W.F. Wong, A. Hayyan, Z. Salleh, O. Mohd-Ali, Natural deep eutectic solvents: cytotoxic profile, SpringerPlus 5 (2016) 913 , https://doi.org/10.1186/s40064-016-2575-9.

[24] M.K. Hadj-Kali, H.F. Hizaddin, I. Wazeer, L. El blidi, S. Mulyono, M.A. Hashim, Liquid-liquid separation of azeotropic mixtures of ethanol/alkanes using deep eutectic solvents: COSMO-RS prediction and experimental validation, Fluid Phase Equilib. 448 (2017) 105-115, https://doi.org/10.1016/ j.fluid.2017.05.021.

[25] A.S.L. Gouveia, F.S. Oliveira, K.A. Kurnia, I.M. Marrucho, Deep eutectic solvents as azeotrope breakers: liquid-liquid extraction and COSMO-RS prediction, ACS Sustain. Chem. Eng. 4 (2016) 5640-5650, https://doi.org/10.1021/ acssuschemeng.6b01542.

[26] F. Bezold, M.E. Weinberger, M. Minceva, Computational solvent system screening for the separation of tocopherols with centrifugal partition chromatography using deep eutectic solvent-based biphasic systems, J. Chromatogr., A 1491 (2017) 153-158, https://doi.org/10.1016/ j.chroma.2017.02.059.

[27] F. Bezold, M.E. Weinberger, M. Minceva, Assessing solute partitioning in deep eutectic solvent-based biphasic systems using the predictive thermodynamic model COSMO-RS, Fluid Phase Equilib. 437 (2017) 23-33, https://doi.org/ 10.1016/j.fluid.2017.01.001.

[28] T. Aissaoui, Y. Benguerba, I.M. AlNashef, Theoretical investigation on the microstructure of triethylene glycol based deep eutectic solvents: COSMO-RS and TURBOMOLE prediction, J. Mol. Struct. 1141 (2017) 451-456, https:// doi.org/10.1016/j.molstruc.2017.04.009.

[29] T. Aissaoui, I.M. AlNashef, Y. Benguerba, Dehydration of natural gas using choline chloride based deep eutectic solvents: COSMO-RS prediction, J. Nat. Gas Sci. Eng. 30 (2016) 571-577, https://doi.org/10.1016/j.jngse.2016.02.007.

[30] L.P. Silva, L. Fernandez, J.H.F. Conceição, M.A.R. Martins, A. Sosa, J. Ortega, S.P. Pinho, J.A.P. Coutinho, Design and characterization of sugar-based deep eutectic solvents using conductor-like screening model for real solvents, ACS Sustain. Chem. Eng. 6 (2018) 10724-10734, https://doi.org/10.1021/ acssuschemeng.8b02042.

[31] G. Della Gatta, D. Ferrq, Enthalpies of fusion and solid-to-solid transition, entropies of fusion for urea and twelve alkylureas, Thermochim. Acta 122 (1987) 143-152, https://doi.org/10.1016/0040-6031(87)80114-4.

[32] G. Della Gatta, M. Jóźwiak, B. Brunetti, L. Abate, Enthalpies and entropies of fusion and of sublimation at the temperature $298.15 \mathrm{~K}$ of thiourea and sevenN-alkylthioureas, J. Chem. Thermodyn. 32 (2000) 979-997, https://doi.org/ 10.1006/jcht.2000.0662.

[33] S. Roy, A. Riga, K. Alexander, Experimental design aids the development of a differential scanning calorimetry standard test procedure for pharmaceuticals, Thermochim. Acta 392-393 (2002) 399-404, https://doi.org/10.1016/S00406031(02)00317-9.

[34] M.A. Peña, B. Escalera, A. Reíllo, A.B. Sánchez, P. Bustamante, Thermodynamics of cosolvent action: phenacetin, salicylic acid and probenecid, J. Pharm. Sci. 98 (2009) 1129-1135, https://doi.org/10.1002/jps.21497.

[35] M.J.S. Monte, D.M. Hillesheim, Thermodynamic study on the sublimation of 2 phenylacetic, 4-phenylbutyric, and 5-phenylvaleric acid, J. Chem. Eng. Data 46 (2001) 1601-1604, https://doi.org/10.1021/je010153h.

[36] B. Tong, R.-B. Liu, C.-G. Meng, F.-Y. Yu, S.-H. Ji, Z.-C. Tan, Heat capacities and nonisothermal thermal decomposition reaction kinetics of D-mannitol, J. Chem. Eng. Data 55 (2010) 119-124, https://doi.org/10.1021/je900285w.

[37] A.J. Lopes Jesus, L.I.N. Tomé, M.E. Eusébio, J.S. Redinha, Enthalpy of sublimation in the study of the solid state of organic compounds. Application to erythritol and threitol, J. Phys. Chem. B 109 (2005) 18055-18060, https:// doi.org/10.1021/jp051621n.

[38] A.R. Hansen, K.D. Beyer, Experimentally determined thermochemical properties of the malonic acid/water system: implications for atmospheric aerosols, J. Phys. Chem. A 108 (2004) 3457-3466, https://doi.org/10.1021/ jp0376166.

[39] B. Schröder, L.M.N.B.F. Santos, I.M. Marrucho, J.A.P. Coutinho, Prediction of aqueous solubilities of solid carboxylic acids with COSMO-RS, Fluid Phase Equilib. 289 (2010) 140-147, https://doi.org/10.1016/j.fluid.2009.11.018.

[40] M.V. Roux, M. Temprado, J.S. Chickos, Vaporization, fusion and sublimation enthalpies of the dicarboxylic acids from C4 to C14 and C16, J. Chem. Thermodyn. 37 (2005) 941-953, https://doi.org/10.1016/j.jct.2004.12.011.

[41] R. Nikolic, J. Tripkovic, D.H. Kerridge, Phase changes in acetamide-salt systems: melting points and latent heat of fusion of pure acetamide and acetamide-ammonium chloride, Thermochim. Acta 146 (1989) 353-360, https://doi.org/10.1016/0040-6031(89)87104-7.

[42] W.V. Steele, R.D. Chirico, A. Nguyen, I.A. Hossenlopp, N.K. Smith, Determination of ideal-gas enthalpies of formation for key compounds, AICHE Symp. Ser. (1990) 138-154.

[43] J. Rowlinson, Molecular thermodynamics of fluid-phase equilibria, J. Chem. Thermodyn. 2 (1970) 158-159, https://doi.org/10.1016/0021-9614(70) 90078-9.

[44] J.A.P. Coutinho, S.I. Andersen, E.H. Stenby, Evaluation of activity coefficient models in prediction of alkane solid-liquid equilibria, Fluid Phase Equilib. 103 (1995) 23-39, https://doi.org/10.1016/0378-3812(94)02600-6.

[45] J.R. J Gmehling, B. Kolbe, M. Kleiber, Chemical Thermodynamics for Process Simulation, 2012. http://eu.wiley.com/WileyCDA/WileyTitle/productCd3527312773.html.

[46] A. Klamt, Conductor-like screening model for real solvents: a new approach to the quantitative calculation of solvation phenomena, J. Phys. Chem. 99 (1995) 
2224-2235, https://doi.org/10.1021/j100007a062.

[47] A. Klamt, V. Jonas, T. Bürger, J.C.W. Lohrenz, Refinement and parametrization of COSMO-RS, J. Phys. Chem. A 102 (1998) 5074-5085, https://doi.org/ $10.1021 /$ jp980017s.

[48] F. Eckert, A. Klamt, Fast solvent screening via quantum chemistry: COSMO-RS approach, AIChE J. 48 (2002) 369-385, https://doi.org/10.1002/ aic.690480220.

[49] COSMOtherm, C3.0 Release 17.01, COSMOlogic GmbH \& Co KG, http://www. cosmologic.de.

[50] TURBOMOLE V7.1 2016, A Development of University of Karlsruhe and Forschungszentrum Karlsruhe GmbH, 1989-2007, TURBOMOLE GmbH, since, 2007. available from: http://www.turbomole.com.

[51] C. Steffen, K. Thomas, U. Huniar, A. Hellweg, O. Rubner, A. Schroer, TmoleX-A graphical user interface for TURBOMOLE, J. Comput. Chem. (2010) n/a-n, https://doi.org/10.1002/jcc.21576.

[52] A. Klamt, F. Eckert, W. Arlt, COSMO-RS: an alternative to simulation for calculating thermodynamic properties of liquid mixtures, Annu. Rev. Chem. Biomol. Eng. 1 (2010) 101-122, https://doi.org/10.1146/annurev-chembioeng-073009-100903.

[53] C.R. Ashworth, R.P. Matthews, T. Welton, P.A. Hunt, Doubly ionic hydrogen bond interactions within the choline chloride-urea deep eutectic solvent, Phys. Chem. Chem. Phys. 18 (2016) 18145-18160, https://doi.org/10.1039/
C6CP02815B.

54] E.A. Crespo, L.P. Silva, M.A.R. Martins, L. Fernandez, J. Ortega, O. Ferreira, G. Sadowski, C. Held, S.P. Pinho, J.A.P. Coutinho, Characterization and modeling of the liquid phase of deep eutectic solvents based on fatty acids alcohols and choline chloride, Ind. Eng. Chem. Res. 56 (2017) 12192-12202, https://doi.org/10.1021/acs.iecr.7b02382.

[55] D.O. Abranches, L.P. Silva, M.A.R. Martins, L. Fernandez, S.P. Pinho J.A.P. Coutinho, Can cholinium chloride form eutectic solvents with organic chloride-based salts? Fluid Phase Equilib. 493 (2019) 120-126, https:// doi.org/10.1016/j.fluid.2019.04.019.

[56] D.R. Kirklin, Enthalpy of combustion of acetylsalicylic acid, J. Chem. Thermodyn. 32 (2000) 701-709, https://doi.org/10.1006/jcht.1999.0650.

[57] F. Cilurzo, E. Alberti, P. Minghetti, C.G.M. Gennari, A. Casiraghi, L. Montanari, Effect of drug chirality on the skin permeability of ibuprofen, Int. J. Pharm. 386 (2010) 71-76, https://doi.org/10.1016/j.ijpharm.2009.10.053.

[58] C.M. Wassvik, A.G. Holmén, C.A.S. Bergström, I. Zamora, P. Artursson, Contribution of solid-state properties to the aqueous solubility of drugs, Eur. J Pharm. Sci. 29 (2006) 294-305, https://doi.org/10.1016/j.ejps.2006.05.013.

[59] S. Romero, P. Bustamante, B. Escalera, M. Cirri, P. Mura, Characterization of the solid phases of paracetamol and fenamates at equilibrium in saturated solutions, J. Therm. Anal. Calorim. 77 (2004) 541-554, https://doi.org/10.1023/B JTAN.0000038993.61782.ba. 